\title{
A emancipação dos corpos pela arte feminista
}

Ana Beatriz Mauá Nunes ${ }^{1}$

GIUNTA, Andrea. Feminismo y arte latino-americano: historia de artistas que emanciparan el cuerpo. Buenos Aires: Siglo Ventiuno Editores, 2018.

Resenha recebida em: $31 / 08 / 2021$

Resenha aprovada para publicação em: 08/10/2021

Em 2018, a Pinacoteca de São Paulo recebeu a exposição "Mulheres radicais: arte latino-americana, 1960 a 1985”. Com curadoria de Cecilia Fajardo-Hill e Andrea Giunta, reuniu centenas de obras de artistas latino-americanas atuantes desde os anos 1960, problematizando a exclusão dessas mulheres do rol de consagração artística, a concepção de uma arte latino-americana e a própria categoria de "arte feminista" e "arte de mulheres". Antes de chegar ao Brasil, "Mulheres Radicais" passou pelo Hammer Museum e Brooklyn Museum, reforçando a importância de se pensar a atuação das artistas latino-americanas a partir de categorias de interpretação próprias à realidade do continente. A exposição é fruto do trabalho de pesquisa, docência e crítica das duas curadoras, cujas trajetórias de pesquisa são fundamentais para a crítica de arte feminista na América Latina.

No mesmo ano de Mulheres Radicais, Andrea Giunta lançou "Feminismo y arte latino-americano: historia de artistas que emanciparan el cuerpo”, obra na qual se aprofunda em reflexões lançadas na exposição, congregadas às problemáticas abordadas pela historiadora ao longo de sua trajetória, como vanguardas, internacionalismo, gênero e política. O livro em questão dedica-se a pensar as relações entre arte, gênero e militância desde os anos 1960 na América Latina. O argumento central de Giunta reside na ideia de que o feminismo artístico e seus campos de ação adjacentes constituíram a

\footnotetext{
1 Doutoranda em História Social pela Universidade de São Paulo (PPG/USP). E-mail:
} ana.beatriz.nunes@usp.br. Orcid: https://orcid.org/0000-0003-0305-4779 
maior transformação na economia simbólica e política das representações da arte da segunda metade do século XX. Nesse contexto, o corpo foi dispositivo fundamental de crítica e expressão de subjetividades dissidentes em relação aos lugares socialmente normalizados para as mulheres.

Embora dialogue com referências da crítica feminista de arte, como Linda Nochlin e Griselda Pollock, Giunta pontua limitações às interpretações propostas por tais autoras, situadas na Europa e nos Estados Unidos. Ainda que a crítica feminista de arte tenha avançado desde "Why there have been no great Women Artists?", (NOCHLIN, 1971), especialmente no que diz respeito à problematização de noções de cânone artístico e da necessidade de incorporar classe e raça enquanto categorias de análise, a inserção de mulheres no mundo das artes está distante da paridade. Para a autora, tal ausência pode ser constatada em diversas instâncias do campo artístico: no institucional, pela ausência de pesquisadoras, críticas e artistas em instituições de arte; no mercado de arte, pelas disparidades na precificação de obras, e no âmbito acadêmico, pela escassez de trabalhos monográficos sobre vida e obra de artistas mulheres. Afinal, o mundo das artes não está apartado das hierarquias de poder que se materializavam no campo da economia, política e cultura. No caso das artistas latino-americanas, constata-se sua "dupla invisibilidade": por serem mulheres e latino-americanas, essas artistas se deparam com obstáculos ainda mais pungentes. Assim, os aportes teórico-metodológicos advindos da crítica feminista de arte produzida na Europa e Estados Unidos seriam insuficientes para compreender as especificidades da arte produzida por mulheres na América Latina.

A saída teórica proposta por Giunta para contornar tal problema historiográfico e político em relação à incompreensão da trajetória de artistas mulheres latino-americanas é contribuição fundamental para a crítica feminista de arte. Em vez de pensar regionalismos e excepcionalidades do contexto latino-americano, a autora indica a urgência de historicizar os conceitos e ferramentas de análise. Para contornar a exclusão 
e sub-representação de mulheres artistas, seria necessário situar o problema em uma perspectiva histórica, considerando contextos e particularidades de sociedades e contextos diferentes. Além disso, ao se pensar a categoria da "arte latino-americana", Giunta propõe que esta não seja percebida como homogênea, mas constituída a partir das semelhanças e diferenças nas trajetórias de diferentes artistas. A autora defende, então, a necessidade de se teorizar a respeito daquilo que uma história normativa e patriarcal desclassificou e invisibilizou.

Giunta utiliza como exemplo a ideia de que o feminismo artístico teria sido inaugurado na Europa e Estados Unidos e chegado à América Latina com certo atraso. $\mathrm{Na}$ perspectiva da autora, houve a incapacidade de a crítica e a historiografia situadas nesses países mobilizarem lentes de análise adequadas para compreender o panorama latino-americano em suas circunstâncias políticas e sociais. Assim, a relação com o marxismo, a repressão das ditaduras latino-americana, a radicalização da luta armada e as formas como se inseriram nas problematizações a respeito das representações dominantes não foram devidamente exploradas. Não se conduziram debates em torno da formação de uma consciência feminista própria às mulheres latino-americanas, a qual não necessariamente se materializa em formações militantes feministas nos moldes dos países europeus e Estados Unidos. Portanto, contra a ideia de uma importação do feminismo via Europa e Estados Unidos, Giunta relembra como o feminismo latino-americano percorreu um caminho próprio, concomitante ao desenvolvimento dessas ideias em outros lugares. Por exemplo, ao mesmo tempo em que Cindy Sherman, Judy Chicago e Miriam Schapiro atuam no Women Arts Program, em Fresno, Califórnia, em 1971, a argentina Maria Luísa Bemberg realiza seus primeiros curta-metragens, El mundo de la mujer (1972) vinculados à sua militância na União de Mujeres Argentinas.

Neste sentido, mais que a ausência das mulheres no campo artístico, Giunta constata a inexistência ou escassez de estudos dedicados a compreender as 
especificidades do trabalho de mulheres artistas latino-americanas. Quando esses trabalhos existem, são baseados em termos como qualidade e excelência, responsáveis por nomear critérios que recorrem a percepções tautológicas: a arte de qualidade é arte boa, e a arte boa é arte de qualidade, sem problematizar como esses critérios de apreciação artística, gostos e valores são construídos historicamente e, portanto, sujeitos a transformações. Por este motivo, é fundamental pensar em perspectivas que analisam, contextualizam e destacam significados e articulações nas obras de artistas mulheres do continente latino-americano.

Para embasar os questionamentos lançados por ela nos primeiros momentos do livro, Giunta se debruça sobre uma análise empírica. No primeiro capítulo, Arte, feminismo y politicas de representación, a autora pondera a respeito das exclusões e lugares comuns na cena artística argentina. Para isso, constrói um panorama sobre os Salões Nacionais do país entre os anos de 1911 e 2017, considerando a proporção entre homens e mulheres no montante de todos os premiados. Giunta conclui que as mulheres estiveram mais distantes das categorias mais apreciadas, como pintura e escultura. Com a inclusão do prêmio de gravura, cerâmica e têxtil, as mulheres passaram a ter maior participação, embora a paridade ainda estivesse distante. Nesse panorama centenário, Giunta demonstra os obstáculos e contradições para a inserção das mulheres no âmbito artístico.

No capítulo seguinte, Giunta trabalha com as trajetórias da artista colombiana Clemencia Lucena e da argentina Maria Luisa Bemberg. Em Artistas entre activismos. Clemencia Lucena y Maria Luísa Bemberg, una aproximación comparativa, a autora se propõe a explorar as relações entre o feminismo, arte e a militância de esquerda nas obras das artistas elencadas. No caso de Lucena, a Giunta ressalta que embora a artista não tenha se identificado enquanto feminista, suas obras problematizaram os papeis sociais e estereótipos associados à feminilidade. Em 1971, Lucena passou integrar o MOIR, Movimiento Obrero Independiente y Revolucionario, e se dedica a retratar 
mulheres da classe trabalhadora, mulheres militantes e sua relação com militância e maternidade. As temáticas das suas obras, por vezes, foram consideradas ingênuas diante do terror de Estado perpetrado pelo governo ditatorial argentino. No caso de Bemberg, Giunta explorou sua atuação na União Argentina de Mulheres e a radicalidade do cinema experimental ao qual se dedicou, ainda na década de setenta. Nesse capítulo, Giunta pondera a respeito das relações entre militância de esquerda e feminismo, identificando as contradições inerentes a esse processo e os desafios e obstáculos enfrentados pelas mulheres que se propuseram a enfrentar esses temas.

Dedicado à Narcisa Hirsch, o terceiro capítulo, Un retrato in abstensia. Narcista Hirsch y el cine experimental en Buenos Aires, reflete sobre as suas produções audiovisuais, como Taller, de 1975. Para Giunta, Hirsch se enquadra na categoria das artistas mulheres que produziram obras críticas às relações de gênero, mas não se identificavam enquanto feministas. As temáticas abordadas por elas são atravessadas pela constituição de uma identidade em trânsito, do mundo social e cultural da Argentina nos anos 1960 e 1970 e a efervescência do mundo das artes. Além de explorar a temática da condição social das mulheres, Hirsch, assim como Maria Luisa Bemberg, foi uma das pioneiras no cinema experimental argentino dos anos 1960.

O quarto capítulo, Feminismos artísticos en México. Manifestos, conferencias exposiciones y activismos, contempla o contexto mexicano de produção artística de mulheres. Em 1975, na ocasião da celebração Ano Internacional da Mulher, Cara Stellweg organizou uma publicação, a Revista Artes Visuales. Embora as artistas, ativistas, pesquisadoras e críticas ali reunidas concordassem a respeito da ausência de representatividade das mulheres no campo latino-americano das artes, as causas e saídas eram tema para debate. A efervescência desse encontro rendeu realização de seminários, espaços fundamentais para pensar a atuação de mulheres artistas no contexto global e mexicano. Giunta constata que essas reuniões se tornaram palco para exposições de obras, em que não havia apenas crítica aos papeis sociais atribuídos às mulheres, mas 
vislumbrava-se um ativismo feminista efetivo. Para Giunta, o feminismo artístico no México foi ponto fora da curva, seja pela sua continuidade no tempo ou pelos recursos e instrumentos mobilizados em obras, instalações e performances. No entendimento da autora, o país esteve apartado das condições que outras artistas mulheres se viram forçadas a enfrentar no contexto das ditaduras latino-americanas.

O quinto capítulo relata a trajetória da artista uruguaia Nelbia Romero. Em Archivos, performance y resistência: Nelbia Romero y el arte de Uruguay bajo la dictadura, Giunta contempla o trabalho de Romero a partir da instalação Sal-si-puedes, de 1983. O título da instalação remetia a Salsipuedes, o nome do encontro entre as forças militares da República Oriental do Uruguai e grupos indígenas, cujo desdobramento foi o extermínio dessa população. Sal-si-Puedes era a atualização do massacre que constituiu o processo de instauração do Estado nacional uruguaio para as "condições de censura e violência impostas pela ditadura." (GIUNTA, 191). O trabalho trazia manequins partidos ao meio e cobertos de tinta vermelha. Essa era uma alusão aos mortos e desaparecidos durante a Ditadura Civil-Militar Uruguaia. Para a análise da instalação de Romero, Giunta se debruça sobre arquivos históricos e conclui que o trabalho da artista é fruto do impulso historicizante de muitas expressões de arte contemporânea. Em tais trabalhos, o retorno ao arquivo e às fontes são formas de revisitar o passado a partir do presente: "El archivo actualiza el pasado en el presente" (GIUNTA, 2018, p. 192).

No último capítulo, Sentir, pese a todo: Paz Errázuriz, fotografia y dictadura en Chile, Giunta pondera em qual medida pode-se afirmar que as ditaduras são constitutivas da contemporaneidade artística na América Latina. Para a historiadora, essas questões advêm do entendimento de que a este tema se articularam sensibilidades particulares que se tornam eloquentes nos contextos sócio-históricos. Por isso, precisam ser explicitadas para audiências pouco familiarizadas com as experiências em que essas obras foram gestadas. Entre as fissuras da cultura do medo, articulou-se a cultura da 
resistência. Nesses atos de resistência, não considera somente as manifestações evidentes contra as forças repressivas, mas também os diferentes signos, linguagens e manifestações artísticas que foram formas de dissidências. Foi por meio dessas práticas que se articularam comunidades interpretativas. Nessa perspectiva, Giunta analisa a fotografia de Paz Errárzuriz, identificando “conspirações da imagem”, lidas a partir de contextos específicos. Seria uma forma de trazer à tona o que não pode ser nomeado. Numa liberação de sentidos, a proposta de Errrárzuriz é “capturar el momento en que la imagen disse." (GIUNTA, 2018, p. 201)

Ao final do livro, percorremos trajetórias de artistas situadas em diversos países da América Latina, com graus de adesão variados em relação ao que se entende enquanto arte feminista. $\mathrm{O}$ denominador em comum para essas artistas que exploraram formatos diversos - cinema, performance, fotografia e pintura - é a centralidade do corpo como ferramenta de contestação diante das variadas formas de violência vivenciadas pelas mulheres em contextos de repressão e violência. $\mathrm{O}$ corpo enquanto espaço de opressão e constrição é ressignificado, consolidando-se como caminho de saída e resistência. Ainda que individual e subjetivo, integra expressão de caráter coletivo, de movimento que se adensa ao longo dos anos, adquirindo contornos específicos ao contexto latino-americano.

Como forma de contornar tal cenário, Giunta propõe novas lentes de análise para investigar o que pode ser definido enquanto feminismo artístico ou artistas feministas na América Latina. Em vez de considerar a adesão formal das artistas enquanto validação, Giunta elenca quatro categorias de análise possíveis para compreender o trabalho dessas mulheres, considerando as especificidades de seus países de origem e os contextos social e político nos quais estavam incluídas. Como demonstra a autora, houve artistas que, sem haver necessariamente se identificado como feministas ou artistas mulheres, pautaram sua atividade artística em um sistemático processo de investigação centrado no corpo e nas violências de gênero sofridas por elas. Nesse caso, à análise detida das 
obras soma-se uma investigação que se debruçou sobre documentos arquivísticos e pôde demonstrar como essas artistas, embora tivessem pontos de contato com as agendas do feminismo euronorteamericano, se pautavam a partir dos contextos e estratégias locais.

$\mathrm{Na}$ primeira perspectiva, estão situadas as artistas que produzem obras de cunho feminista e se identificam com o movimento. Na segunda categoria, estão as mulheres que se auto representam como artistas mulheres, que atuam naquilo que Giunta denomina de propostas de una arte feminina. Nas iconografias trabalhadas, identificam-se elementos relacionados a esferas tradicionalmente associadas ao feminino, como maternidade e espaço doméstico. Há também o terceiro tipo, abrangendo mulheres que tiveram práticas transgressoras para os parâmetros existentes, que ocuparam espaços inéditos para as mulheres enquanto artistas, mas que não se reconheceram enquanto artistas mulheres ou artistas feministas. Finalmente, o quarto eixo de análise seria de mulheres que perpetuaram enquanto artistas uma estética predominantemente patriarcal, sem qualquer tipo de adesão ao feminismo estético.

Embora a obra de Giunta seja de fundamental relevância para aproximar o/a leitor/a sobre a trajetória de mulheres artistas situadas em diversas regiões da América Latina que utilizaram o corpo como meio de contestação - fosse à opressão de gênero ou como resistência às ditaduras militares instauradas no continente e que ainda permanecem pouco conhecidas do público em geral -, sua principal contribuição reside nas proposições de caráter teórico-metodológico por ela trazidas, fundamentais para os estudos situados nos campos da História, Arte e Gênero na América Latina. 